\title{
Proceeding
}

Supplementary Issue: Winter Conferences of Sports Science. Costa Blanca Sports Science Events, 24 April 2020. Alicante, Spain.

\section{Teachers' perspectives about contents and learning aim of physical education in Italian primary school}

\author{
FRANCESCA D'ELIA \\ University of Salerno, Italy
}

\begin{abstract}
The physical education (PE) in the Italian primary school and its teaching and organizational issues have long been a key topic of the political and scientific debate, however the various actions carried out so far have not been enough to recognize contents and methods of physical and sports education correctly oriented in an educational way, often reducing the time of curricular PE or the project experiences of physical literacy and sport to mere physical-technical exercises. The aim of this work is to develop the essential didacticmethodological contents and to define a model of core curriculum of Sport and Exercise Sciences degrees for teaching of PE in primary school and for sport education in sports associations for leisure and recreational activities. To this end will be conducted an analysis of ministerial documents for the identification of the main educational aspects of the contents and learning outcomes of PE in primary school. Then discussion with primary school teachers has been realized, through focus groups content-focused on PE at school as provided by National Guidelines and on specific projects carried out in collaboration between Italian Ministry of Education and Italian Olympic Committee.
\end{abstract}

Keywords: Core curriculum; Teaching methods; Physical literacy.

\section{Cite this article as:}

D'Elia, F. (2020). Teachers' perspectives about contents and learning aim of physical education in Italian primary school. Journal of Human Sport and Exercise, 15(2proc), S279-S288. doi:https://doi.org/10.14198/ihse.2020.15.Proc2.19

\section{Corresponding author. University of Salerno, Italy.}

E-mail: fdelia@unisa.it

Supplementary Issue: Winter Conferences of Sports Science. Costa Blanca Sports Science Events, 24 April 2020. Alicante, Spain.

JOURNAL OF HUMAN SPORT \& EXERCISE ISSN 1988-5202

(c) Faculty of Education. University of Alicante

doi:10.14198/jhse.2020.15.Proc2.19 


\section{INTRODUCTION}

In Italy at primary level of education the curriculum is defined through National Guidelines, in force from school year 2012/2013 (MIUR 2012). According to these Guidelines, the general aim of school is the harmonious and comprehensive development of the individual, according to the principles of the Italian Constitution and the European cultural tradition, to be achieved through the promotion of knowledge, respect for individual diversity and the active involvement of students and their families. The reference for these new guidelines is the Framework for key competences for lifelong learning set up by the European Parliament and the Council of the European Union through the Recommendation of 18 December 2006 that identifies eight key competences needed for personal fulfilment, a healthy and sustainable lifestyle (Gaetano, 2016, Tiziana et al, 2017), employability, active citizenship and social inclusion. Specifically, the purpose of primary education is to enable pupils to acquire the fundamental knowledge and skills to develop basic cultural competence.

The subjects taught during the 5 years of primary school are: Italian, English, history, geography, mathematics, sciences, technology, music, art, physical education, Catholic religion (optional) and Citizenship Education (Masi \& Santi, 2015). Each subject has goals for the development of skills, to be reached at the end of primary school, which are mandatory for teachers. The National guidelines also set, for each subject, the learning outcomes that indicate the experience fields, knowledge and skills which are needed to reach the goals for the development of competences. According them, through PE at the end of primary education "the student acquires self-awareness through the perception of his own body the mastery of movement and postural patterns in the continuous adaptation to the contingent temporal spatial variables. He uses body language and movement to communicate and express his moods also through dramatization and rhythmic, musical and dance experiences. He goes through a plurality of experiences that allow him to develop sport skills also as an orientation towards future sports practice. He experiences different technical gestures. He acts by respecting the basic safety criteria for itself and for others, both during physical activity (PA) and using apparatus and transfers his competence to the school and extracurricular environment. $\mathrm{He}$ identify some essential principles related to one's psycho-physical well-being related to the care of one's body, to a correct diet and to the prevention of the use of addictive substances. He understands during game and sport activities, the value of the rules and the importance of respecting them" (Miur 2012). These are very ambitious goals if we consider some teaching and organizational issues, such as teacher's lack of competences on PE, inadequacy of school facilities and lack of equipped gyms, the limited time dedicated to teach PE, that in some cases make it difficult to achieve the PE learning outcomes.

\section{The teacher's training}

In Italy PE is taught by generalist teachers, to which has been required a specific degree in order to teach, which includes some university credits (up to 9 credits, just over 200 hours of study on a total of 7500 hours of the degree course), intended for the study of the teaching methods of PA, however these credits are not sufficient to enable them to teach effectively the PE (D'Elia, 2019ab, D'Elia et al, 2018). So, to guarantee a real and qualified teaching to children through adequate and targeted interventions with effects on physical development, learning, prevention and socialization, the Legislative decree no. 992 of December 2018 provided for the introduction of the specialist teacher of PE in primary school. The effective and qualified performance of PE, under the responsibility of "dedicated" and specialized teachers (Raiola et al., 2018), could offer the opportunity to grow and develop in a healthy way, with balance and awareness, reaching learning outcomes, not only on motricity and health (coordination development and physical efficiency), but also on cognitive functions and life skills. The Ddl 992/2018 has the merit of having highlighted the debate 
on the need of a qualified teaching of PE in primary school, however the implementation methods have not yet been defined, so Italian primary school still wait for specialist PE teachers.

\section{School facilities (Ministerial decree $n$. 94/2019)}

The theme of school construction is often at the centre of the political debate, especially when the inadequacy of school buildings (in terms of safety) emerges during climatic or catastrophic events, but also when the structural limits prevent the full development of the planned educational activities or they even determine designs that cannot envisage specific activities precisely because of the shortage or inefficiency of the buildings. In the school the gyms are the structures most affected by problems of adequacy and safety, although the presence of gyms and / or sports facilities inside school buildings are particularly important for curricular and extracurricular teaching activities, holding activities, projects and initiatives aimed at children and youth global development. Teachers and students face daily with lack or inadequacy of buildings, and considering the serious structural deficiencies of Italian schools in terms of sports facilities, for the three-year period 2018-2020 the Italian Ministry of Education has invested substantial resources to allow new constructions or the safety of existing buildings to be allocate to gyms and / or sports facilities with particular interest in areas with a high rate of territorial deprivation or lacking in other school sports facilities or in areas characterized by a high rate of early school leaving.

\section{The PE taught time}

At primary level there are not specific subject timetables, except for English and Catholic religion, and PE is practiced for 1 or 2 hours a week for a total of 33 or 66 hours a year, depending on the weekly teaching timetable that has four options:
A. 24 hours a week,
B. 27 hours a week,
C. up to 30 hours a week, including additional teaching activities to the 27 -hour timetable (i.e. up to 3 extra hours per week),
D. 40 hours a week, including the lunchtime meal, known as 'full time'.

The classes that adopt the option A would hardly be able to reserve one or two hours weekly for PE and to develop the part of the curriculum intended for the achievement of specific learning outcomes of $P E$, so with 24 hours per week, they could exclusively adopt an interdisciplinary and transversal approach to PE.

In schools that adopt the 27 hours model basically only one hour per week is spent to teach PE, while in the 30-hours model, as well as for full time, it is possible to teach PE two hours a week and to plan specific contents and activities to achieve development goals on physical level, such as promotion health, wellbeing and healthy lifestyles, on personal level, such as awareness of body and confidence in one's physical skills, as well as a general sense of well-being and greater security and self-esteem, sense of responsibility, patience, courage, mental balance and on social level such as integration within society, sense of solidarity, social interaction, team spirit, fair play and respect of rules and of the others, as well as wider human and environmental values (Russo et al, 2019a,b; Valentini et al., 2018b).

In primary school PE has taught in the same manner of the other subjects as well as all theoretical knowledge. The main problem is the practice activity that the primary teachers have not the skills and competencies to learn PE. So, the Sport class project gives a solution by supporting primary teachers with external Sport school tutors from Italian Olympic Committee CONI which have the bachelor degree in Exercise and sport science. They teach in curricular period together the primary teacher and participates for planning educational activity in class team organization. 
Considering these specific teaching and organizational issues, this study aimed to develop the essential didactic-methodological contents of PE and to define a model of core curriculum of Sport and Exercise Sciences degrees for teaching of PE in primary school, that can be adopted also for sport education in sports associations for leisure and recreational activities.

To this end it is useful to conduct an analysis of ministerial documents on PE and sport in primary school. In this way, to have the opinions by discuss with primary school teachers on content ministerial documents about PE and specific education of PE as provided by National Guidelines and on Sport class project experiences carried out in collaboration between Minister of Education and CONI by down top manner.

\section{METHODS}

The study design adhered to the consolidated criteria for reporting qualitative research, typical one for educative mission. It is complex and original for the particular investigation to do on the follow up mode together down top way. First step is archive research by documental approach. Document analysis has been carried out by reviewing National Guidelines for primary school curriculum and the Sport Class project to identify the main educational aspects of the contents and learning outcomes of PE and sport practiced in primary school.

Secondly, in order to explore the teacher's perspectives with mode down-top, on PE a semi-structured method such as focus groups (Krueger, 1994) was used; it has been characterized by low directivity in conducting and low structuring of the track. Focus group were conducted with primary school teachers to know the aspects they considered most relevant, their educational priorities, conceptual and linguistic categories, the way they articulate their reasoning in order to obtain a deeper understanding of the factors that influence children's PE at school. Every group is made by one teacher for single macro-subjects that is made by linguistic area, scientific and mathematical area (including PE knowledge) and anthropological area. The group discussion has been self-managed: the moderator has set the themes and provided some interaction rules, then letting the debate be articulated freely and intervening only if there are problems in the group dynamics or excessive deviations from the main topic.

Finally, to enlarge the focus group method in Team class council dedicated to planning with participation of Sport school tutor of CONI to discuss about methodological approach for PE. In the Figure 1 the scheme of Methods.

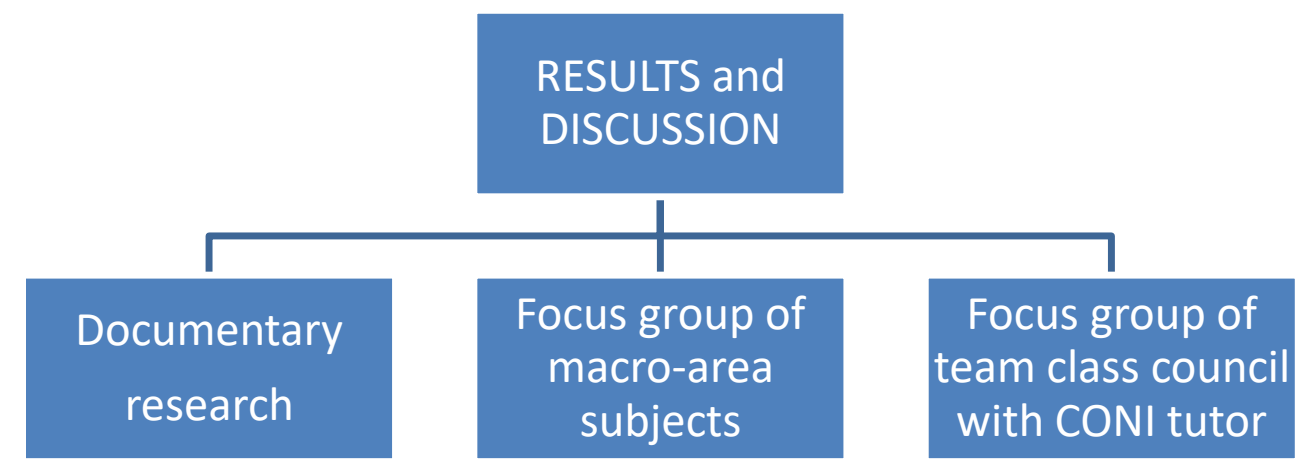

Figure 1. Method scheme. Own source. 


\section{RESULTS AND DISCUSSION}

Physical education according to National Guidelines for the curriculum of the first cycle

According to the National Guidelines for the curriculum of the first cycle of education, the goals for the development of competences and the specific learning outcomes of PE in Italian primary school are related to four areas:

1. The body and its relation to space and time,

2. Body language as a communicative-expressive code,

3. Play, sport, rules and fair play,

4. Health and wellness, prevention and safety.

In each area teachers are called to carry out activities for the learning of skills that do not concern only the physical development but also the cognitive, social, personal, relational and emotional one (Russo et al., $2019 \mathrm{a}, \mathrm{b} ;)$.

1. Referring to the relation of body with space and time

Teaching activities should be oriented in promotion of experiences that require to coordinate and use the different motor milestones initially combined together in a subsequent form and then in simultaneous form (run / jump, grab / throw, etc.). The experiences aimed at stimulating the body-space and body-time relationship will allow the child to recognize and evaluate trajectories, distances, executive rhythms and temporal successions of actions, learning to organize his movement in space in relation to himself, to objects, to the others (Di Domenico et al., 2019). The development of knowledge and skills in this specific area produces learnings that are not limited to the physical development as they represent fundamental prerequisites for school tasks and the development of other skills, such as reading and writing skills.

2. The second learning area aims to develop body language as a communicative-expressive modality The hours of PE, but not only those, should stimulate the creative and original use of the body, emphasizing its expressive and emotional meanings, through dramatization and dance, starting from the elaboration and execution of simple sequences of movement or simple individual and collective choreography to come to use the body and movement to communicate and express their attitudes. Body and movement must be acknowledged as languages that the child should be able to use like the others, not only to express himself, but also to dialogue with others, in order to effectively communicate (Valentini et al., 2019a, 2018a).

3. About play, sport, rules and fair play student should know and correctly apply the execution methods of different game-sport

School should become a place where children can experience multi-sports, that is the possibility of practicing different sports in the form of a game to get to know and practice them even in extra-curricular contexts. He also should know how to use traditional games by applying indications and rules; as well as being fun and dynamic, the most interesting thing about these games is that they have been passed down from generation to generation and they are widespread in different cultures, so their practice can be an opportunity to relate with others. He should participate actively in the various forms of play, also organized in the form of a competition, collaborating with others, and he should respect the rules in sports competition; knowing how to accept defeat with balance and live victory by expressing respect for losers, accepting diversity, showing a sense of responsibility, so PE realizes also a value and an emotional training. 
4. With reference to health and wellness, prevention and safety

Student should adopt adequate behaviours for the prevention of accidents and for safety in the various living environments, he should discern the relationship between nutrition and exercise in relation to healthy lifestyles and he have to acquire awareness of physiological functions (cardio-respiratory and muscle) and their changes in relation to physical exercise. Children do little PA, too many children are physically inactive and do not reach the recommended levels of PA, also for reasons related to going to school with motorized vehicles, playing little outdoors and not doing enough structured sports activities (Sgrò et al., 2019, 2017). Schools and families are called to collaborate in the creation of conditions and initiatives that increase the natural predisposition of children to PA (Valentini et al., 2019, b). He should experience active and passive safety, postural education, good practices, perception of fatigue and well-being, respiratory education and relaxation.

\section{Physical activity and sport in the curriculum of PE}

In addition to teaching of PE in primary schools, the Italian Ministry of Education implements projects aimed at promoting healthy lifestyles and enhancing diversity. Sport and physical activities also become tools to prevent obesity, violence, bullying, racial and gender discrimination. The activities are aimed at spreading a correct culture of sport, to avoid early school leaving, to facilitate the inclusion of the weak and to encourage the active participation of children with disabilities (Caldin, 2014).

Sport is configured, within this path, as a natural expansion of knowledge also with a view to social inclusion.

Among school sport policies, currently, the Sport class project assumes an important meaning because of its main goal that is to enhance physical and sports education in primary school for its transversal values and for the promotion of correct and healthy lifestyles, to promote well-being with a view to social inclusion and according to the National Guideline for the first cycle curriculum. The project is addressed to $4^{\text {th }}$ and $5^{\text {th }}$ level and it provides to flank primary school teachers with School Sports Tutors, that are graduated in Sport and Exercise Sciences. The activities are carried out during the two weekly hours of PE, one hour of which with the support of the school sports tutor. The purpose is to allow teachers to be able to independently and effectively carry out physical and sports education by sharing a part of the PE curriculum with experts that have been trained for these specific purposes. The project also aim to fulfil:

- Inclusion paths for children with disabilities and other special educational needs,

- Games at the end of the school year,

- A value path concerning the theme of "fair play" for the year 2019/2020,

- Supplying of sports equipment, exclusively for each of the newly enrolled educational institutions,

- Compatibility with other local projects referring to the promotion and enhancement of PE in primary school.

Sport class project since 2014 has involved an increasing number of schools, going from $32 \%$ to $59 \%$ of participation at national level, interesting more and more students, favouring the practice of physical and sport activities and spreading the foundations of a culture of movement and sport.

Starting from the specific learning outcomes to be achieved through PE, the sport project realized at school and in consideration of the highlighted organizational and didactic issues, we introduced didactics opportunities of physical education teaching in primary school (D'Isanto, 2019a, 2016) and proceeded through a focus-group to know the perspectives of teachers and from the discussion emerged the following factors influencing quality and quantity of PE and sport practiced at school: 
1. Teacher belief and value system about PE: all teachers held positive beliefs toward PE and believed that schools have an important role of prevention and promotion of healthy lifestyles through the sport and PE.

2. Children needs and behaviours: the importance and positive value on sport and PE by teachers was linked to the positive effects that movement activities, through games and sport, have on physical and social development of children. In particular, they also believe that PE and sport can improve behaviours towards teachers, adults and rules (D'Alonzo et al., 2013).

3. Educational priority of teachers: despite the positive views that widely teachers held toward PE, they feel they don't have adequate skills for teaching this subject and when they meet organizational issues such as lack of time, lack of space or inadequate sports facilities, they establish educational priorities which often leads to marginalize the hours of PE, allocating the little time and the reduced resources for the development of other subject that are considered more effective for children development.

4. Teacher-sport tutor relationship. Experts sport tutor were perceived by teachers to be an important position for realizing PE. However, the teachers not always understand the spirit of sport class project and the role of sport tutor, so they did not co-conduct the lessons, but let the expert do it alone, believing that they could not be effective. In some cases, it emerged thoughts about the technical nature of the proposed activities and of the teaching methods that was perceived too far from the school goals.

5. Parents. All teachers agreed that parents and, more generally all significant others in the children's life, can contribute to realize PE and sport through the collaboration between school and family.

As following the Figure 2 on results and discussion synthetizes the data.

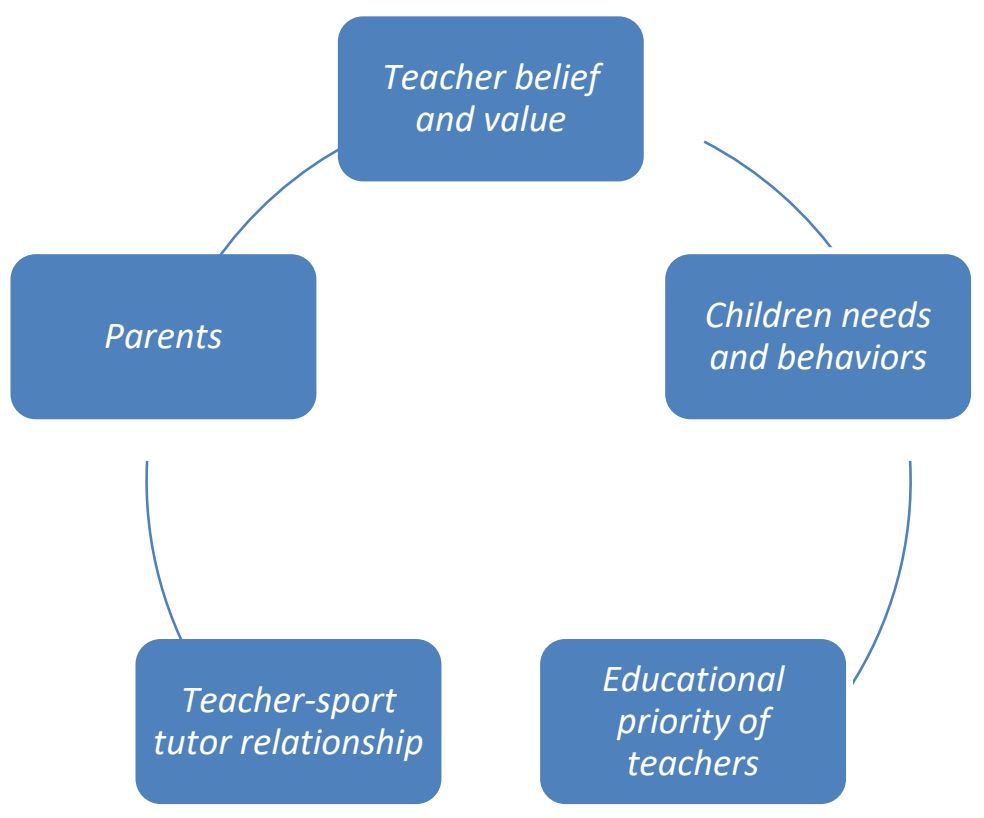

Figure 2. Results and discussion scheme about factors that influence PE. Own source. 


\section{CONCLUSION}

From document analysis PE in primary school has a well-defined profile and its many educational values are enhanced, many interventions and investments in favour of PE and sport have been made, but from the perceptions of the teachers emerge some discrepancies between what is declared and expected and what is actually achieved. In particular, teacher training should be reviewed and school organizational issues about PE taught time and facilities should be realistically analysed to highlight the difficulties that teachers encounter and which often prevent the development of the part of the curriculum dedicated to physical education.

First of all, the training courses for general teachers should be rethought, providing adequate training on the teaching methods of PE (Raiola, 2017, 2014, 2013, 2011), thus also promoting a broader vision of this subject that has effects not only on physical, social and health development, but produces effects also on the cognitive and emotional development of the child. Furthermore, in view of introducing specialist teacher of PE a core curriculum for PE teaching in the degree courses in Exercises and Sport Sciences should be designed (Raiola, 2020, 2019ab, D'Isanto 2019), and it would be useful to encourage more general teachers to engage a more collaborative approach that take into account the contribution of PE and of the specialist teacher to the whole educational process.

In addition to presence training could be designed an online training (D'Elia, Raiola, 2109) in mix mode to evaluate the main aspects both of them and to deep the virtual and augmented reality in physical and sport activities (Viscione, D'elia, 2019).

In the Figure 3 the main conclusion have represented in a holistic vision to apply for an iconic mode to enlarge the understandings on the basics elements of the study.

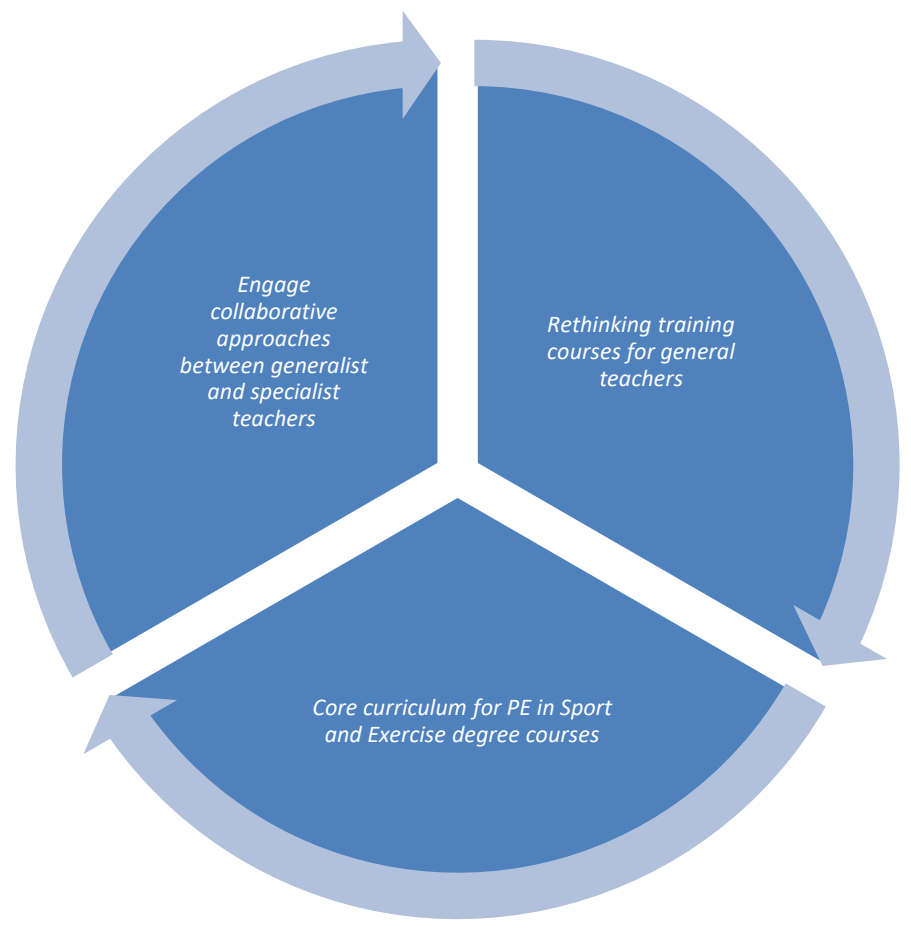

Figure 3. Conclusion. Own source. 


\section{REFERENCES}

MIUR - Italian Ministry of Education (2012). National guidelines for the curriculum.

Ministerial Decree n. 94/2019 (MIUR - Italian Ministry of Education). Financing of interventions for the safety and / or new construction of school buildings to be used in gyms and / or sports facilities.

Caldin R. (2014). Educatability and possibility, difference and diversity: the contribution of Special Pedagogy, Education sciences \& society, 2014, 65-77.

D'Alonzo L., Maggiolini S., Zanfroni E. (2013). Tra presente e passato: gestione della classe e nuove sfide educative. La parola agli insegnanti. Form@re, Open Journal per la formazione in rete ISSN 1825-7321 Numero 3, Volume 13, anno 2013, pp. 4-16.

D'Elia F. (2019a). The core curriculum of University training to teach physical education in Italy. Journal of Physical Education and Sport, vol. 19 (Supplement Issue 5), 1755-1758 ISSN:2247-806X.

D'Elia, F. (2019). The training of physical education teacher in primary school. Journal of Human Sport and Exercise, 14(1proc), S100-S104. https://doi.org/10.14198/hhse.2019.14.Proc1.12

D'Elia, F., Mazzeo, F., \& Raiola, G. (2018). The core curriculum in the university training of the teacher of physical education in Italy. Journal of Human Sport and Exercise, 13(2proc), S413-S420. https://doi.org/10.14198/ihse.2018.13.Proc2.25

D'Elia, F., Raiola, G. (2019). Sport and Exercise Sciences Degrees in Italy: Comparison Between Online and Traditional Teaching Models, Communications in Computer and Information Science, 1091, pp. 209-216. https://doi.org/10.1007/978-3-030-31284-8_16

D'Isanto, T. (2019a). State of art and didactics opportunities of physical education teaching in primary school, Journal of Physical Education and Sport, 19, art. no. 257, pp. 1759-1762.

D'isanto, T. (2019b). Physical and sport education between Italian academic system and European Research Council structure panel, Journal of Human Sport and Exercise, 14(Proc1), pp. S66-S76. https://doi.org/10.14198/ihse.2019.14.proc1.08

D'Isanto, T. (2016). Pedagogical value of the body and physical activity in childhood [Pedagoška vrijednost tijela i tjelesne aktivnosti u djetinjstvu]Sport Science, 9, pp. 13-18.

Di Domenico, F., Fattore, S., Pignato, S., D'isanto, T. (2019). Relationship between motor learning and reaction capacity in motor task, Journal of Human Sport and Exercise, 14 (Proc4), pp. S1030-S1037. https://doi.org/10.14198/ihse.2019.14.proc4.65

Gaetano, A. (2016). Relationship between physical inactivity and effects on individual health status, Journal of Physical Education and Sport, 16, pp. 1069-1074.

Krueger R.A. (1994). Focus Group. A Practical Guide for Applied Research. London, Sage .

Masi D., Santi M. (2015). Learning democratic thinking: a curriculum to philosophy for children as citizens. Journal of Curriculum Studies, Volume 48, 2016, 136-150. https://doi.org/10.1080/00220272.2015.1088064

Raiola G., (2020). The Movement and Sport Science in Italy Towards the European Research Council, Physical Culture and sport. Studies and research vol. 86. https://doi.org/10.2478/pcssr-2020-0011

Raiola, G. (2019a). Comparison of exercise and sport sciences epistemology between European research council structure panel and Italian academic system Sport Science, 12, pp. 112-120.

Raiola, G. (2019). Survey on exercise and sport sciences in Italy. Journal of Human Sport and Exercise, 14(4proc), S1163-S1168. https://doi.org/10.14198/hhse.2019.14.Proc4.81

Raiola, G. (2017). Motor learning and teaching method, Journal of Physical Education and Sport, 17, art. no. 236, pp. 2239-2243.

Raiola, G. (2014). Motor control and learning skills according to cognitive and ecological dynamic approach in a vision on behaviorism, cognitive, Gestalt and phenomenology theories, Mediterranean Journal of Social Sciences, 5 (15), pp. 504-506. https://doi.org/10.5901/mjss.2014.v5n15p504 
Raiola, G. (2013). Body knowledge and motor skills, Knowledge Cultures, 1 (6), pp. 64-72.

Raiola, G. (2011). A study on Italian primary school rules: Neurophysiological and didactics aspects $n$ physical education and sport. Journal of Physical Education and Sport, 11 (2), pp. 43-48.

Raiola, G., D'Elia, F., \& Altavilla, G. (2018). Physical activity and sports sciences between European Research Council and academic disciplines in Italy, Journal of Human Sport and Exercise, 13(Proc2), S283-S295. https://doi.org/10.14198//hse.2018.13.proc2.13

Russo, G., Nigro, F., Raiola, G., Ceciliani, A. (2019a). Self-esteem in physically active middle school students, Journal of Physical Education and Sport, 19, art. no. 295, pp. 1984-1988.

Russo, G., Nigro, F., Raiola, G., Ceciliani, A. (2019b). The role of the extra physical activity on memory storage and psychosocial features, Journal of Human Sport and Exercise, 14 (Proc4), pp. S948S956. https://doi.org/10.14198/ihse.2019.14.proc4.57

Sgro, F., Quinto, A., Platania, F., Lipoma, M. (2019). Assessing the impact of a physical education project based on games approach on the actual motor competence of primary school children, Journal of Physical Education and Sport, 19, art. no. 111, pp. 781-786.

Sgrò, F., Quinto, A., Messana, L., Pignato, S., Lipoma, M. (2017). Assessment of gross motor developmental level in italian primary school children. Journal of Physical Education and Sport, 17 (3), art. no. 192, pp. 1954-1959.

Tiziana, D., Antonetta, M., Gaetano, A. (2017). Health and physical activity [Zdravlje i tjelesna aktivnost]Sport Science, 10 (1), pp. 100-105.

Valentini, M., Mancini, M., Raiola, G., Federici, A. (2019a). Digital and non-verbal communication in preschool: A systematic review, Journal of Human Sport and Exercise, 14 (Proc4), pp. S997-S1016. https://doi.org/10.14198/ihse.2019.14.proc4.62

Valentini, M., Virgili, L., D'isanto, T., Federici, A. (2019b). Body moving towards the "WELL-BEING", Journal of Physical Education and Sport, 19, art. no. 303, pp. 2036-2046.

Valentini, M., Bernardini, C., Beretta, A., Raiola, G. (2018a). Movement and language development as an early childhood twin strategy: A systematic review Sport Mont, 16 (3), pp. 107-112.

Valentini, M., Riccardi, F., Raiola, G., Federici, A. (2018b). Educational research: Motor area and relational area during children's personality development, Journal of Physical Education and Sport, 18, art. no. 327, pp. 2157-2174.

Viscione, I., D'elia, F. (2019). Augmented reality for learning in distance education: The case of e-sports, Journal of Physical Education and Sport, 19, pp. 2047-2050.

\section{(ब) $\odot \Theta$}

This work is licensed under a Attribution-NonCommercial-NoDerivatives 4.0 International (CC BY-NC-ND 4.0). 